\title{
Development and characterization of an oat TILLING-population and identification of mutations in lignin and $\beta$-glucan biosynthesis genes
}

\author{
Aakash Chawade1,2, Per Sikora22, Marcus Bräutigam 1,3, Mikael Larsson4, Vivekanand Vivekanand2, \\ Montedar All Nakash ${ }^{3}$, Tingsu Chen 1,5 and Olof Olsson*2,3
}

\begin{abstract}
Background: Oat, Avena sativa is the sixth most important cereal in the world. Presently oat is mostly used as feed for animals. However, oat also has special properties that make it beneficial for human consumption and has seen a growing importance as a food crop in recent decades. Increased demand for novel oat products has also put pressure on oat breeders to produce new oat varieties with specific properties such as increased or improved $\beta$-glucan-, antioxidant- and omega-3 fatty acid levels, as well as modified starch and protein content. To facilitate this development we have produced a TILLING (Targeting Induced Local Lesions IN Genomes) population of the spring oat cultivar SW Belinda.

Results: Here a population of 2600 mutagenised M2 lines, producing 2550 M3 seed lots were obtained. The M2 population was initially evaluated by visual inspection and a number of different phenotypes were seen ranging from dwarfs to giants, early flowering to late flowering, leaf morphology and chlorosis. Phloroglucinol/ $\mathrm{HCl}$ staining of M3 seeds, obtained from 1824 different M2 lines, revealed a number of potential lignin mutants. These were later confirmed by quantitative analysis. Genomic DNA was prepared from the M2 population and the mutation frequency was determined. The estimated mutation frequency was one mutation per $20 \mathrm{~kb}$ by RAPD-PCR fingerprinting, one mutation per $38 \mathrm{~kb}$ by MALDI-TOF analysis and one mutation per $22.4 \mathrm{~kb}$ by DNA sequencing. Thus, the overall mutation frequency in the population is estimated to be one mutation per 20-40 kb, depending on if the method used addressed the whole genome or specific genes. During the investigation, 6 different mutations in the phenylalanine ammonia-lyase (AsPAL1) gene and 10 different mutations in the cellulose synthase-like (AsCsIF6) $\beta$-glucan biosynthesis gene were identified.

Conclusion: The oat TILLING population produced in this work carries, on average, hundreds of mutations in every individual gene in the genome. It will therefore be an important resource in the development of oat with specific characters. The population (M5) will be available for academic research via Nordgen http://www.nordgen.org as soon as enough seeds are obtained.
\end{abstract}

[Genbank accession number for the cloned AsPAL1 is GQ373155 and GQ379900 for AsCsIF6]

\section{Background}

The genus Avena belongs to the grass family Poaceae [1]. It comprises about seventy species, although mainly $A$. sativa, $A$. nuda and $A$. byzantina are those most commonly cultivated on a commercial scale. A. sativa is an economically important crop and ranks sixth in world

* Correspondence: olof.olsson@gu.se

2 Department of Plant and Environmental Sciences, Göteborg University, S40530, Göteborg, Sweden

Full list of author information is available at the end of the article cereal production after wheat, maize, rice, barley and sorghum [2]. Oat is grown for grain and hay and is mostly used as a feed for cattle. In 2008-2009, oat was cultivated on 12.76 million hectares mostly in temperate areas in the USA, Canada and Europe, but also on significant areas in China, Brazil and Australia [3]. Oat is well adapted to a wide range of soil types and performs better than many other small grain cereals on both acidic and alkaline soils [4]. 
Oat seeds have good nutritional value with a high content of essential dietary minerals, unsaturated fatty acids, unique galacto-lipids and the highest levels of globular proteins amongst any cereal. They also have high levels of mixed (1T3), (1T4) $\beta$-D-glucans [5], which are beneficial for digestion and have cholesterol-lowering properties [68]. Moreover, oat contains compounds such as tocopherols, inositol phosphates and avenanthramides which possess antioxidative properties [9].

In the last few years, the awareness-increase of the health-beneficial properties of oats has lead to a heightened consumption in Great Britain and the Scandinavian countries [10]. Even though traditional oat breeding has been successful in continuously improving the beneficial properties of oat, further enhancement is possible. A winter oat may increase the average yield by more than $20 \%$ $[11,12]$, a more easily digestible kernel containing a low lignin hull would increase the energy value of the feed by $15 \%[13,14]$, an oat rich in $\beta$-glucan fibres would further increase the health beneficial properties for humans [6-8] and a low mycotoxin oat would exclude oat products from the new threshold values for mycotoxin levels that will be introduced in the European Union during 2010 [15].

Application of molecular techniques in oat breeding would facilitate the development of more complex characteristics. Although marker assisted mapping programs are in progress $[16,17]$, generation of mutated oat lines by transposons, T-DNA or RNA interference techniques is technically difficult and has not been attempted. This is partly due to the lack of an efficient transformation system and partly due to the large genome size with an estimated $1 \mathrm{C}$ genome weight of $13.23 \mathrm{pg}$, corresponding to about 13,000 Mbp [18]. The fact that cultivated oat is hexaploid [19] and the genome not sequenced complicates the matter even further. Therefore, although several oat ESTs are publicly available, many more will be required to cover the entire transcriptome [20].

One way to increase variation in the breeding process would be to use radiation or chemical mutagens such as EMS (ethyl methanesulfonate). EMS is a highly mutagenic substance that preferentially alkylates guanine bases leading to the DNA-polymerase favoring the placement of a thymine residue instead of a cytosine residue opposite to the O-6-ethyl guanine in the subsequent DNA-replication step. This results in a random point mutation wherein G-C base-pairs (bps) are switched to A-T pairs [21]. Mutations in coding regions can be silent, missense or nonsense and mutations outside coding regions, like promoter mutations resulting in up- or down-regulation of transcription, aberrant splicing of mRNA, altered mRNA stability or changes in protein translation may also occur.
In TILLING, high frequency mutagenesis is combined with molecular based, high precision selection methods. The power of TILLING was first demonstrated in Arabidopsis thaliana [22] and Drosophila melanogaster [23] and has later been successfully applied to a number of plant systems including Arabidopsis [24], barley [25,26], Lotus japonicus [27,28], wheat [29], maize [30], rice [31,32], pea [33], soybean [34] and naked oats [35]. If the mutation frequency is high enough, and the population size large enough, a mutated allele of most, if not all, genes will be present in the population. In combination with an efficient method to identify point mutations, for example the Li-COR method [22], it is possible to apply TILLING to genetically complicated crops as well. The power of the principle was elegantly confirmed by the identification of number of waxy gene mutants in TILLING populations of both tetraploid and hexaploid wheat where the corresponding waxy enzymes in some cases completely lost their activity [29]. Moreover, a plant carrying a triple mutant, which displayed a near null waxy phenotype was also developed [29]. A TILLING-population in a hexaploid oat with a reasonable mutation frequency should therefore, by analogy, be a very useful breeding tool. Although Li-COR based techniques are commonly used for screening for mutations, MALDITOF (Matrix-assisted laser desorption/ionization-timeof-flight mass spectrometer) based assays can also be used. In the MALDI-TOF, samples are ionised and then relocated to the mass analyser where they are separated according to their mass to charge ratio. The ions are then detected and analysed by means of specially developed software.

In this work, a TILLING population for hexaploid oat, consisting of 2550 different mutagenised seed lines was developed and the mutation frequency determined. To screen the population, a method based on MALDI-TOF

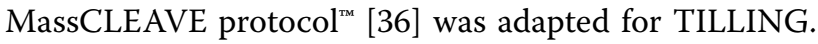
We demonstrated the potential of the oat TILLING population by identifying several different mutations in the oat AsPAL1 and AsCslF6 genes - key genes in the lignin and $\beta$-glucan biosynthetic pathways, respectively. These genes were chosen because they encode traits of great interest to oat breeders. A down-regulation of the $P A L$ will result in modified, more easily extractable lignins with increased digestibility [37,38], which will in-turn increase the feed value of the crop. Since $\beta$-glucans are becoming very important functional food ingredients, an oat variety with increased or modified $\beta$-glucan content in the seed will significantly increase the value of the crop. Oat $\beta$-glucans have a health claim both in the US and in the EU and a regular consumption of oat $\beta$-glucans has been linked to a number of health beneficial effects like lowering of blood cholesterol levels, a decrease of the 
general glycemic index of ingested food and some protection against colon cancer [39].

\section{Results}

\section{Development of an oat TILLING-population}

To determine the optimal survival rate for TILLINGapplications, an EMS titration kill curve for oat seeds was established at different EMS concentrations (Figure 1). In total 8 different EMS concentrations were used and $\sim 200$ seeds were treated at each concentration. An EMS concentration of $0.9 \%(\mathrm{v} / \mathrm{v})$ was finally chosen for large-scale mutagenesis, giving a predicted survival rate of approximately 37\% (Figure 1). Approximately 9000 seeds were mutagenised, germinated and the surviving M1 plants were allowed to set seeds. Of the 2880 mutants that germinated, 2800 mutants produced filled panicles, while the rest died, did not flower or produced empty panicles.

M2 seeds were harvested from each of the M1 lines and used to plant out the M2 population. Out of 2800 seeds planted, 2600 germinated (Figure 2). The entire M2 life cycle was then followed and phenotypic abnormalities on individual plants in the segregating population were recorded. Normally, phenotypic changes are extremely rare in a population of non-mutated Belinda that has been inbred for generations (personal communication with oat breeders). However, in the TILLING-population chlorosis $(2.3 \%)$, semi-dwarfness $(1.3 \%)$, giants $(0.6 \%)$, dwarf and high tiller $(0.6 \%)$, late/early flowering and late senescence were frequently observed (Figure 3 ). In total, ca $5 \%$ of the mutagenised Belinda population had visually detectable phenotypic alterations.

Genomic DNA was extracted from two-week-old leaves from each of the 2600 different lines in the M2 population by the cetyltrimethylammonium bromide (CTAB) method [40]. After flowering and seed production an average of 100 seeds (varying from 5 to 150) were

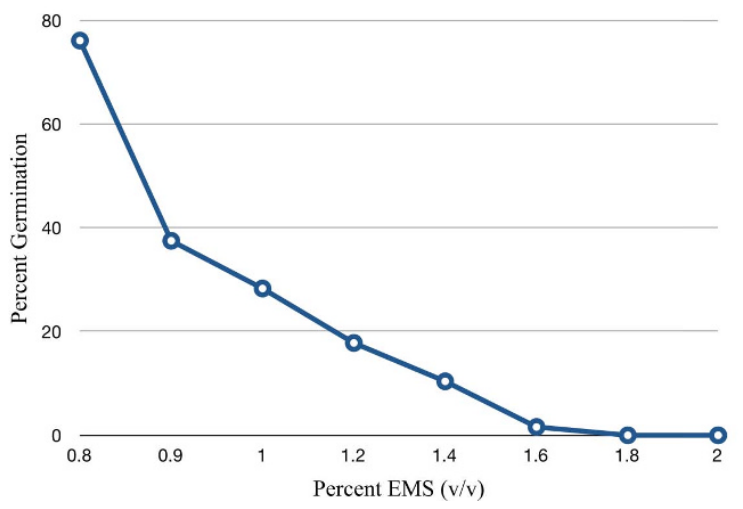

Figure 1 Titration of EMS concentration. Y-axis: \% germinating seeds, X-axis: \% EMS concentration

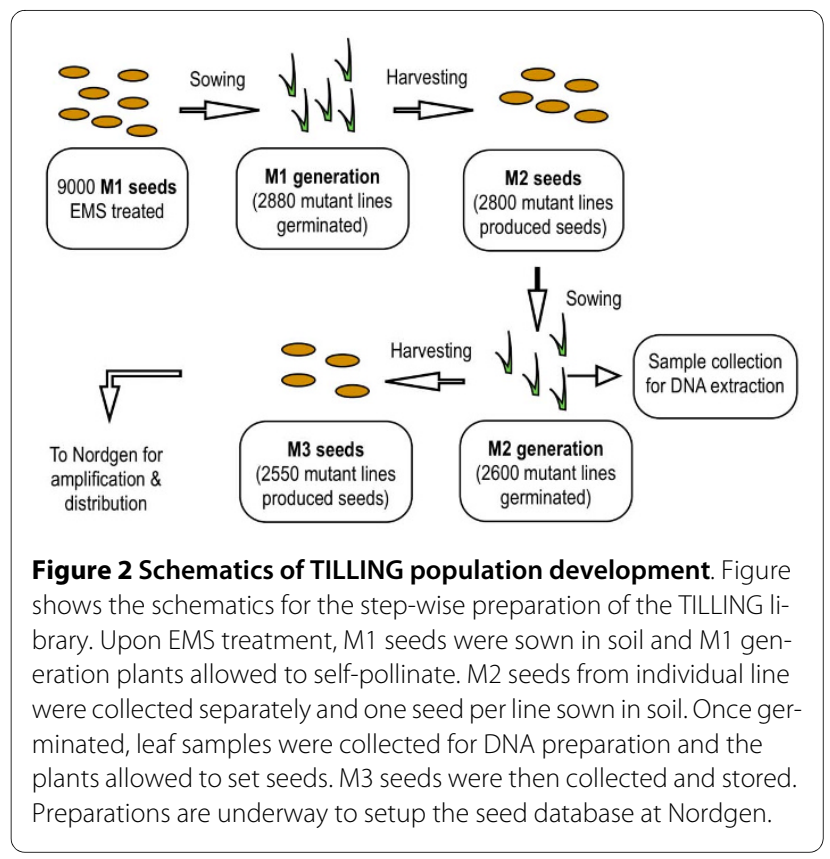

harvested from each of the 2550 fertile lines. These seeds make up the M3 TILLING-population (Figure 2).

\section{Biochemical analysis of lignin content}

The Wiesner phloroglucinol-HC1 assay [41] was used to screen for mutants with differential lignin deposition in the seed coat. M3 seeds from each line of approximately $70 \%$ of the population (1824 independent, random M2 mutagenised lines) were stained (see methods). Typically, whole seeds, whole de-husked seeds and de-husked cross-sectioned seeds were tested. Non-mutated Belinda was used as a positive high lignin control and the Canadian variety A. C. Assiniboia (AAFC, Canada) as a low lignin control. From these, 17 mutant lines were identified that showed lower stain intensity in the husk compared to Belinda. A representative result is shown in Figure 4.

\section{Lignin quantification}

Although phloroglucinol- $\mathrm{HCl}$ assay is a rapid method, it is not quantitative. Therefore, the lignin content in the mutant candidates was measured with the acetyl bromide method. This method is relatively simple and appropriate for small sample sizes. The method allows complete dissolution of lignin and hence provides precise absorbance values for total lignin content with little interference from non-lignin products [42]. For each line, 10 individual seeds were weighed and measured. The lignin content in Belinda was $41.04 \mathrm{~g} / \mathrm{kg}$ and $20.84 \mathrm{~g} / \mathrm{kg}$ in Assiniboia, a Canadian low lignin variety. This is in good agreement with previous lignin tests on Assiniboia [43]. In the identified mutant lines, lignin contents were in the range of 


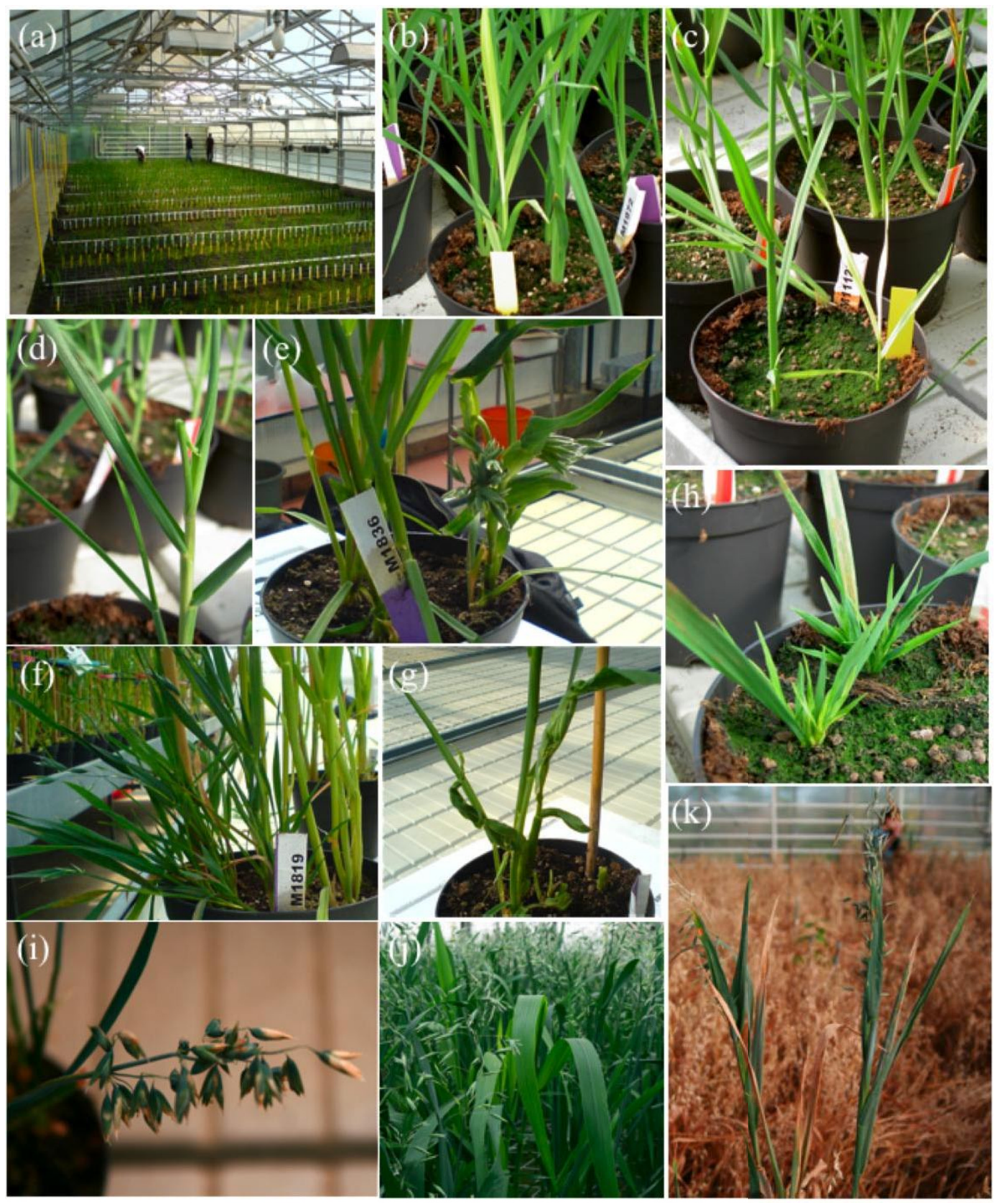

Figure 3 Examples of phenotypes seen in the $\mathbf{M} 2$ segregating oat Tilling population. (a) M2 population growing up (about $50 \%$ of the total population shown). (b) and (c) Chlorotic mutation. (d) - (g) Morphological mutations. (h), (i) Dwarf. (j), (k) Broad leaved and tall 


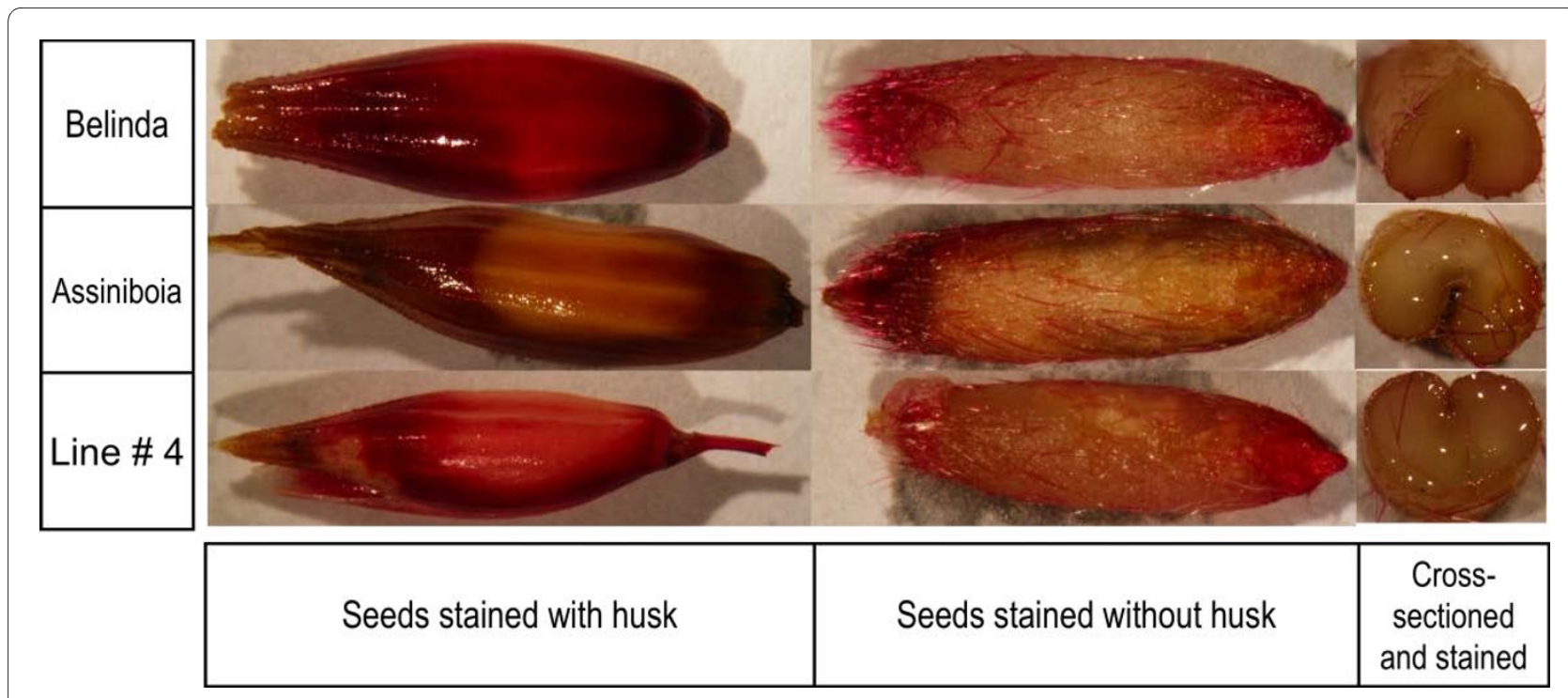

Figure 4 Phloroglucinol staining of a mutant with low-lignin content. Picture shows phloroglucinol stained seeds from Belinda, Assiniboia and a mutant with low lignin content. Seeds were either stained with husk or first de-husked and then stained. Alternatively, seeds were de-husked, crosssectioned and then stained.

20-34 g/kg. Line \#4 was the lowest with $20.31 \mathrm{~g} / \mathrm{kg}$, which is in the same range as in Assiniboia (Figure 5).

\section{Estimation of the mutation frequency by RAPD-PCR}

Even though the number of visual phenotypes in a population indirectly reflects the number of mutations in the genome, it is not feasible to estimate the mutation fre- quency in this way due to gene redundancy, silent mutations and the fact that oat is hexaploid. Therefore, to better approximate the mutation frequency a RAPD-PCR (Random Amplification of Polymorphic DNA) method was exploited. Briefly, using short random $10 \mathrm{bp}$ primers, chromosomal DNA from non-mutated Belinda was amplified. After standardizing PCR reactions with

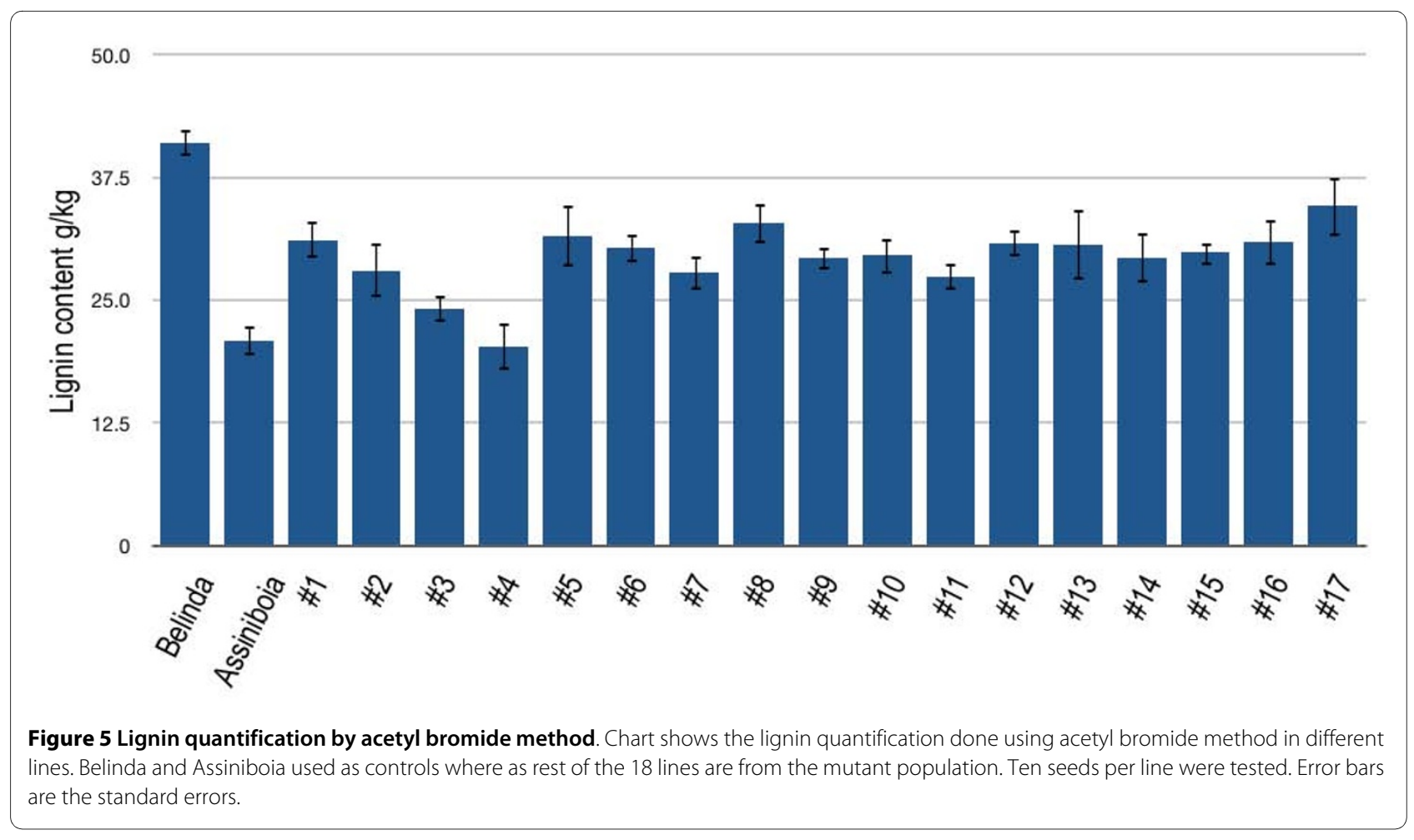


Belinda wt DNA as a template, 16 different bands were routinely obtained with the particular primer combination used. When analyzing DNA from 252 independent lines using the same PCR conditions, 4 mutants were found where the band pattern differed from non-mutagenised Belinda (data not shown). A gain or loss of a band will occur if the particular chromosomal sequence to which the random primer binds, has at least one mutated bp. Assuming a target size of $20 \mathrm{bp}$ ( 2 primers), 16 bands covers a target of $320 \mathrm{bp}$. One mutation per 63 lines therefore indicates an average mutation frequency in each line of approximately one mutation per $20 \mathrm{~kb}$.

\section{Cloning of PAL and CsIF genes}

A genomic AsPAL1 sequence of $3209 \mathrm{bp}$ including one 1133 bp long intron (Figure 6a) and a 2358 bp long partial AsCslF6 mRNA was obtained (Figure 6b). The sequences of both genes have been submitted to Genbank, accession number for AsPAL1 is GQ373155 and GQ379900 for AsCslF6.

\section{Mutant discovery by MALDI-TOF analysis}

Primers were designed and amplification products separated on agarose gels to confirm the expected product and to rule out unspecific products. Fragments with the expected size from several independent reactions were then sequenced to confirm that only a single sequence had been amplified. In the final PCR reactions, $949 \mathrm{bp}$ from AsCsFl6 and 705 bp from the AsPAL1 gene were amplified (Figure 7) using DNA from the M2 population. During degradation with the adapted MassCLEAVE ${ }^{\mathrm{m}}$ method before the MALDI-TOF fragment separation, $316 \mathrm{bp}$ from AsCslF6 and $45 \mathrm{bp}$ from AsPAL1 were in practice lost as some of the generated fragments became too short or too long to resolve satisfactorily in the MS. In total, 300 lines were analysed for mutations in the AsCslF6 gene and 350 lines for mutations in the AsPAL1 gene. This covered $190 \mathrm{~kb}$ of the AsCslF6 sequences and $231 \mathrm{~kb}$ of $A s P A L 1$ sequences. The screenings yielded 5 AsCslF6 mutations and 6 AsPAL1 mutations, indicating a mutation frequency of one mutation in $38 \mathrm{~kb}$ and one

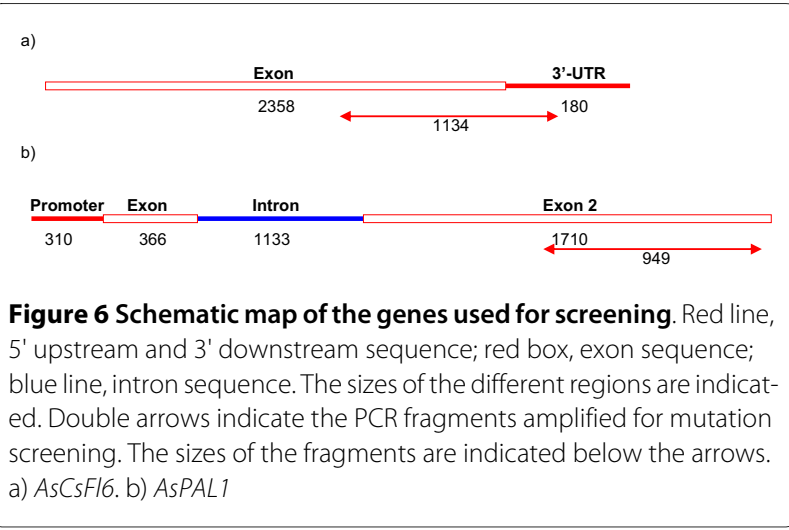

mutation in $38.5 \mathrm{~kb}$, respectively. The entire gene fragments from all identified mutants were DNA sequenced and the mutants confirmed.

\section{Confirmation of MALDI-TOF screening by DNA sequencing}

To estimate the predictive abilities of the MALDI-TOF screening method, using the AsPAL1 gene, 160 of the lines that were screened with MALDI-TOF were subjected to DNA sequencing, adding to $113 \mathrm{~kb}$. This not only confirmed the four AsPAL1 mutations that were previously identified but also showed that there were no other mutations that went undetected by the MALDITOF screening. Therefore it seems like the MALDI-TOF assay is sensitive enough to detect most mutations in a given sequence and that the background noise is low.

\section{Identification of mutations directly by DNA sequencing}

Since the mutation frequency seemed to be high, we attempted to identify mutations directly by DNA sequencing. Using the AsCslF6 specific gene primers we amplified and sequenced the $949 \mathrm{bp}$ fragment from 126 different lines, covering a total of $112 \mathrm{~kb}$. This resulted in the identification of 5 additional AsCslF6 mutations, corresponding to one mutation per $22.4 \mathrm{~kb}$.

\section{Characterisation of identified mutations}

In the AsPAL1 sequence, four $\mathrm{C}$ to $\mathrm{T}$ and two $\mathrm{G}$ to $\mathrm{A}$ transitions were found. Three of these mutations were located in the wobbling base and therefore silent, but 3 led to an amino acid change. These mutations were evaluated by SIFT (Sorting intolerant from tolerant) [44] and PSSM (Position specific scoring matrix) [45] scores. Of the ten mutations found in AsCslF6, five created silent mutations and five corresponded to amino acid changes. Of these, four were $\mathrm{G}$ to $\mathrm{A}$ transitions and one an A to T transversion. The obtained PSSM scores of these mutations were not significant and thus it's unlikely that the identified mutations may cause any phenotypic changes. For further details see Table 1.

\section{Discussion}

TILLING is a good alternative to more direct DNA modifying techniques since seed mutagenesis is easy to apply and relatively independent of genome size and organization [46]. To determine the feasibility of developing an oat TILLING population initial experiments were performed to find an optimal balance between mutation frequency and lethality. Since the oat genome size is very large, it is crucial that the mutation frequency in the final TILLING-population is high. Our aim was to produce a population where mutations in all genes can be found with a high redundancy without having to produce a very large population size, which requires more advanced logistics in handling and maintenance. Screening large populations also becomes laborious, expensive and technically 

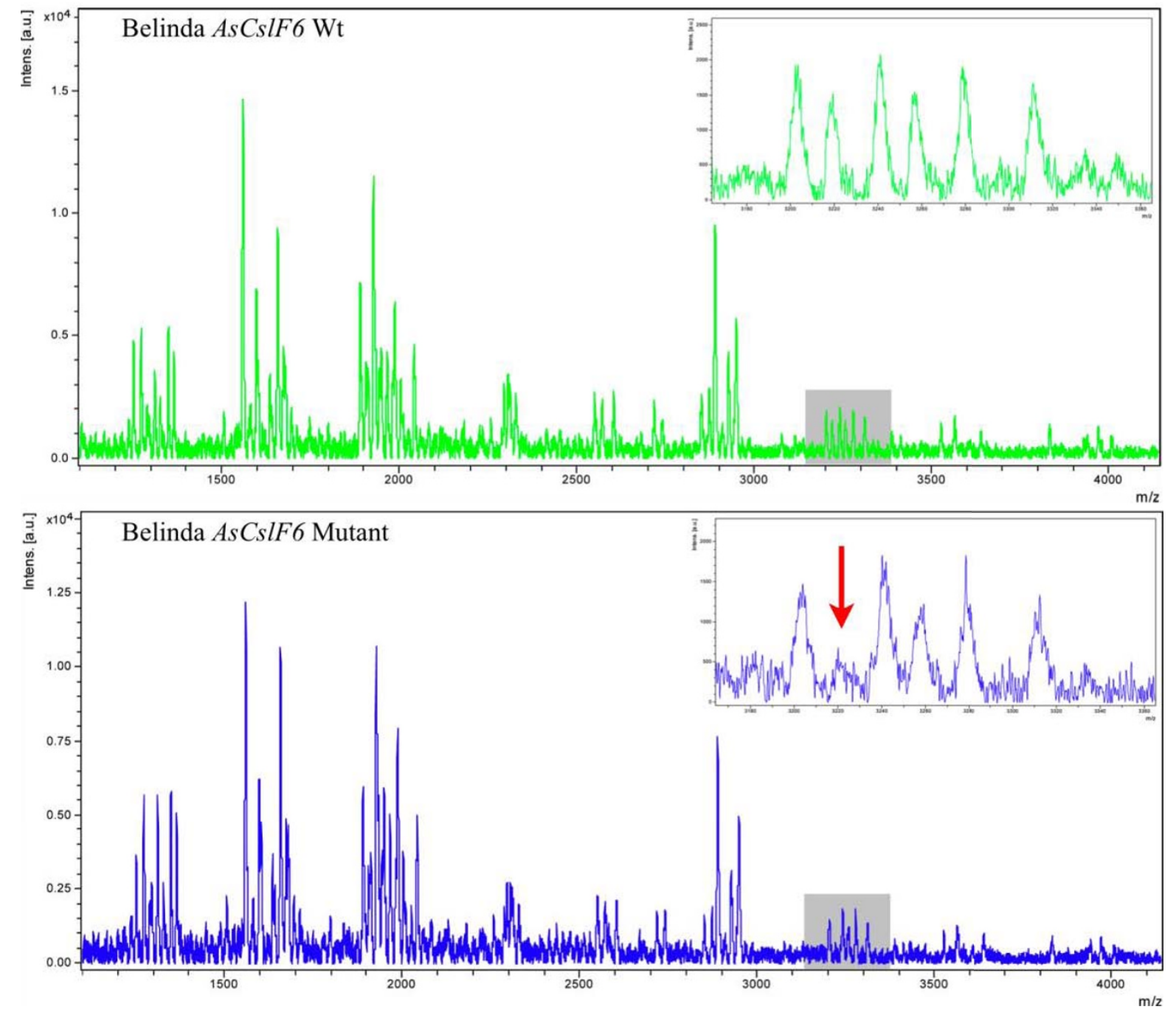

Figure 7 Identification of single nucleotide differences in the AsCsIF6 gene by MALDI-TOF. Amplified PCR fragments were transcribed, cleaved at every Uracil-residue and separated according to size. X-axis indicate the MW of each fragment in Daltons (Da) and the Y-axis denotes intensity in Arbitrary Units (a.u.). The disappearance of an expected peak (red arrow) indicates the appearance of a new cleavage site in the fragment, i.e the introduction of a new Uracil residue. Grey box indicates magnified region.

more demanding. On the other hand, a too high mutation frequency will increase the frequency of deleterious mutations, which if too numerous will kill the plant. After testing different EMS concentrations we settled for $0.9 \%$ $(\mathrm{v} / \mathrm{v})$ or $86.98 \mathrm{mM}$, which gave a germination rate of $37 \%$. This EMS concentration is in the range of what has been used for wheat $(0.75 \%, 1.0 \%$ or $1.2 \% \mathrm{v} / \mathrm{v})$ [29] and maize $(1 \% \mathrm{v} / \mathrm{v})$ [30], whereas for barley three different concentrations were used $(10,20,30 \mathrm{mM}$ corresponding to $0.1 \%$, $0.2 \%, 0.3 \% \mathrm{v} / \mathrm{v}$ ) [25]. The concentration used for rice was much higher $(1.5 \% \mathrm{v} / \mathrm{v})[32]$.

In Avena four genomes, denoted A, B, C and D, have been identified. In nature, 5 different combinations of these genomes, namely AA, CC, AABB, AACC and AACCDD can be found [47]. Belinda, like other commonly cultivated $A$. sativa species, is a natural allo-hexaploid that contains three genomes AA, CC and DD. Such a redundant genomic organization could be a potential complication when identifying specific phenotypes from the TILLING-population. The presence of a specific allele on all three genomes would mean that even if one is mutated other alleles could compensate for the lost function. However, as has been shown in hexaploid wheat, the three genomes often contribute differently to the expression of certain alleles, which also can also vary even in different tissues of the plant [48]. When inspecting the 
Table 1: Identified mutations in the AsPAL1 and AsCsIF6 genes.

\begin{tabular}{|c|c|c|c|c|c|c|}
\hline *Gene & Type & Amino acid & Position & PSSM Shift & SIFT & Method \\
\hline AsPAL1 & $\mathrm{C}$ to $\mathrm{T}$ & Thr to lle & 487 & -6 & Not Tolerated & MALDI-TOF and sequencing \\
\hline AsPAL1 & $\mathrm{C}$ to $\mathrm{T}$ & Thr to Met & 532 & 0 & Not Tolerated & MALDI-TOF and sequencing \\
\hline AsPAL1 & $\mathrm{C}$ to $\mathrm{T}$ & Pro to Ser & 537 & - & Tolerated & MALDI-TOF and sequencing \\
\hline AsPAL1 & $\mathrm{C}$ to $\mathrm{T}$ & Silent & & - & - & MALDI-TOF and sequencing \\
\hline AsPAL1 & $\mathrm{G}$ to $\mathrm{A}$ & Silent & & - & - & MALDI-TOF \\
\hline AsPAL1 & $\mathrm{G}$ to $\mathrm{A}$ & Silent & & - & - & MALDI-TOF \\
\hline AsCsIF6 & $\mathrm{G}$ to $\mathrm{A}$ & Val to Met & & 0 & Tolerated & Sequencing \\
\hline AsCsIF6 & $\mathrm{G}$ to $\mathrm{A}$ & Gly to Arg & & -3 & Tolerated & Sequencing \\
\hline AsCslF6 & $\mathrm{C}$ to $\mathrm{T}$ & Silent & & - & - & Sequencing \\
\hline AsCsIF6 & $\mathrm{G}$ to $\mathrm{A}$ & Silent & & - & - & Sequencing \\
\hline AsCsIF6 & $\mathrm{G}$ to $\mathrm{A}$ & Silent & & - & - & Sequencing \\
\hline AsCsIF6 & $\mathrm{C}$ to $\mathrm{T}$ & Silent & & - & - & MALDI-TOF \\
\hline AsCsIF6 & A to $T$ & Met to Lys & & -3 & Tolerated & MALDI-TOF \\
\hline AsCslF6 & $G$ to $A$ & Silent & & - & - & MALDI-TOF \\
\hline AsCsIF6 & $G$ to $A$ & Gly to Asp & & -2 & Tolerated & MALDI-TOF \\
\hline AsCslF6 & $\mathrm{G}$ to $\mathrm{A}$ & Arg to $\mathrm{His}$ & & -1 & Tolerated & MALDI-TOF \\
\hline
\end{tabular}

*Gene: The genes screened for; Type: detected mutation; Amino acid: the predicted amino acid change in the protein; Position: Position of the changed amino acid in the protein; PSSM and SIFT: significance of change in the amino acids; Method: "MALDI-TOF and sequencing" indicates that the same mutation was identified by both MALDI-TOF and DNA sequencing. Other mutants were either identified by MALDITOF or by DNA sequencing, as indicated.

oat M2 segregating TILLING-population visible phenotypes were indeed observed in about $5 \%$ of the plants (Figure 2). This is surprisingly high considering that in wheat visible phenotypes were seen in only $0.5 \%$ of the cases [29]. To extend the resolution of the phenotypic observations we therefore decided to test a specific biochemical pathway.

We stained individual M3 seeds from 1824 randomly chosen individual lines with phloroglucinol-HCI (Wiesner test) [41]. This test is generally considered to be indicative of aldehyde end groups present in, for example cinnamyl aldehydes and is thus indicative of lignin content and/or structure [49]. The Wiesner test revealed differences in the staining pattern in approximately $1 \%$ of the screened seeds. Again, this is a surprisingly high frequency, which corroborated the phenotypic observations. To verify this, total lignin in seeds from the mutant lines were quantified with the acetyl bromide method. In this assay, bromine replacement of $\alpha$-carbon-OH groups produce a brown-red colored complex, which is dissolved in acetic acid. The intensity of the color is proportional to the amount of lignin [50]. The assay confirmed all 17 of the earlier identified mutants (Figure 5). Since it is not likely that independent mutations have simultaneously occurred in the same lignin gene in all of the three oat genomes, this indicates that at least some mutations are dominant in a way that is normally seen in a diploid plant. More studies are needed to determine if oat is different from wheat in this respect.

To test the mutation frequency more directly on the DNA level, two different approaches were used - RAPD and MALDI-TOF. One was more generally aimed at the whole genome, while the other was directed at specific genes.

By optimising a RAPD-PCR based method for oat genomic DNA the average mutation frequency for the whole genome was calculated. An advantage with this method is that it is relatively fast and simple. When analysing DNA samples from 252 different lines, 4 abnormal electrophoresis patterns were found, corresponding to a mutation frequency of approximately 1 per $20 \mathrm{~kb}$ (data not shown) assuming that only a single bp is sufficient to prevent primer binding. However, this might not always be the case and therefore the calculated mutation frequency will rather underestimate than overestimate the true frequency.

To compare the genome wide mutation frequency to the frequency in specific genes, two different genes, each encoding characteristics important for oat breeders, were chosen as models. The first gene, AsPAL1, encodes a protein that catalyses the first step of the phenyl-propanoid pathway [51]. The second gene, AsCslF6, encodes an 
enzyme involved in the biosynthesis of mixed link 1-3, 1$4 \beta$ - $D$-glucans ( $\beta$-glucans). $\beta$-glucans are water-soluble fibres common in the cell wall of the Poaceae family and are synthesised by one or several members of a very large cellulose synthase superfamily, from which the $C s l C$, $\mathrm{CslH}$ and $\mathrm{CslF}$ genes seem to be most relevant $[52,53]$. These two genes were screened for mutations by MALDI-TOF.

By adapting a MALDI-TOF based SNP screening method to oat TILLING, and by direct DNA sequencing, mutations for the two target genes were identified. In total $533 \mathrm{~kb}$ were covered and 16 mutations were found (Table 1), giving an average mutation frequency of 1 per $33.3 \mathrm{~kb}$. This discrepancy from the RAPD-PCR estimation could reflect the fact that, in contrast to the genome wide estimate where local differences are evened out, factors such as chromosomal location, degree of closed or open chromatin, gene redundancy level etc., can influence the result when focusing on more specific regions. Additional investigations are therefore needed to explain more precisely why the mutation frequency in the chosen genes appears to be lower than the general frequency.

Overall, the mutation frequency in the oat TILLINGpopulation thus appears to be in the same range as previously found in hexaploid wheat (1 mutation/24 kb) [29]. This is much higher than what was described in barley (1 mutation/1000 kb) [25], maize (1 mutation/500 kb) [30], rice (1 mutation/530 kb) [32] and other dicots [28,33,54]. The specific reasons for these differences are not yet known, but presumably larger polyploid genomes like oat and wheat can tolerate more mutations before lethality occurs.

Successful TILLING not only depends on the population size and the mutation frequency, the method used to identify specific mutations in the population is equally important. This is especially a concern with a large, hexaploid genome like oat. Up to now, all, published high-throughput TILLING procedures have utilized a CEL I based mismatch-cleavage enzyme on heteroduplex formations followed by a detection of end-labeled cleavage products on electrophoretic gels $[30,54,55]$. On the other hand MALDI-TOF based methods to identify SNPmutations also have an inherent capacity to combine straightforward sample preparation with high sensitivity and high-throughput and are well documented, especially in clinical applications [36,56,57]. However, to our knowledge MALDI-TOF methods have not been systematically exploited in TILLING. One drawback with current MALDI-methods is their reliance on specialised equipment and software for identifying the mutations. Another potential problem for large scale screening programs is the high costs of the chemicals needed. On the other hand, MS based methods are sensitive, robust and reliable, which minimise redundant experiments and reduce the cost. They also allow the identification of homozygous mutations. In addition, using several alternative cleavage patterns from the same sample, mutations can be pinpointed down to the single bp level, potentially eliminating the need for confirmative DNA sequencing.

Thus, the MALDI-TOF method used here indeed detected mutations with an, up until now, $100 \%$ precision. The final percentage is likely to decrease somewhat as sample size increases. In any case, MALDI-TOF will be good complement or possibly an alternative to CEL I/LiCOR-screening provided that the per-sample cost could be brought down to an acceptable level and throughput increased. Without automation, MALDI-screening is still a low throughput method only allowing one person to screen approximately 288 samples per week, assuming 8hour workdays. We are currently in the process of optimising and automating the protocol for large-scale screening.

A comprehensive analysis of the spectrum of mutations generated by EMS in Arabidopsis was published in 2003 [24]. It was shown that about $50 \%$ of all mutations were missense mutations that altered an amino acid, while approximately $5 \%$ of the mutations were nonsense resulting in premature termination of the target protein. Furthermore, in Arabidopsis, maize and wheat the majority of all mutations were the expected GC to AT transitions $[29,30,54]$. In rice on the other hand, this distribution was somewhat different and only $70 \%$ of recorded mutations were GC to AT [32]. In oat, we have so far identified 16 mutations, out of which 15 were GC to AT transitions (Table 1). Thus, oat seems to be similar to wheat in this respect. Most mutations were missense and silent. So far no nonsense mutation have been found (Table 1). We did not find any examples of small deletions or other rearrangements either, which indicates that the EMS mutagenesis worked as expected.

\section{Conclusions}

In conclusion, a TILLING population of 2550 mutant lines containing a high frequency of mutations is presented. In combination with a high precision and efficient screening method, it is realistic to assume that productive mutations in all alleles in any gene of interest will eventually be identified. Since the genetic basis of a particular mutation then will be known, by repeated back crosses (introgression) especially productive mutations can be introduced to any chosen oat variety by marker assisted selection while the majority of the other mutations will be eliminated in the same process. Useful mutations in different alleles can also be crossed together. The oat tilling population will be deposited in NordGen http:// www.nordgen.org as M5 seeds and will be available for academic purposes as soon as the population has been propagated. Additionally, a mutation-detection and 
screening service will be available to the scientific community for academic research through the company CropTailor AB http://www.croptailor.com.

\section{Methods \\ Plant cultivation}

Oat, Avena sativa v. Belinda a Swedish spring variety was obtained from the SW-collection (Svalöf Weibull AB, Landskrona, Sweden). Plants were grown in a greenhouse under halogen lamps, giving a photon flux density of 240 $\mu \mathrm{mol} / \mathrm{m} 2 / \mathrm{sec}$ with a photo-period of $18 \mathrm{~h}$. Day and night temperatures were $25^{\circ} \mathrm{C}$ and $16^{\circ} \mathrm{C}$ respectively. Plants were grown in five-liter pots or directly on the ground in standard soil for oat growth.

\section{EMS mutagenesis}

Fifty lots of ca 200 seeds were transferred to a $50 \mathrm{ml}$ falcon tube and $30 \mathrm{ml}$ of washing solution $(0.01 \% \mathrm{v} / \mathrm{v}$ Tween 20 in water) was added to each tube. The tubes were gently shaken for $1 \mathrm{hr}$ at $150 \mathrm{rpm}$ at RT. The seeds were washed 2 times with water after which $10 \mathrm{ml} 0.9 \%(\mathrm{v} / \mathrm{v})$ or $86.98 \mathrm{mM}$ EMS in water (M0880 Sigma Aldrich, Inc) was added to the tubes followed by shaking at $150 \mathrm{rpm}$ for 16 hours at RT. The EMS solution was then discarded; seeds were washed three times with water and were vigorously shaken in water for $2 \mathrm{hrs}$. The water was discarded and the seeds were again washed 3 more times with water. The seeds rapidly loose their germination ability at this point and have to be immediately sown. This was done by carefully picking individual seeds with forceps and placing them in a small germination pot with standard soil for oat growth. Seeds were allowed to germinate and the number of germinating seeds was scored.

\section{Biochemical analysis}

From the M3 generation two seeds (with husk) each from 1824 independent mutants were picked and stained with phloroglucinol- $\mathrm{HCl}$ reagent (1\% phloroglucinol in $20 \%$ $\mathrm{HCl})$ for 30 minutes as per the protocol $[41,58]$ in 96 well plates. Seeds that stain different as compared to nonmutated Belinda were re-confirmed by staining several more seeds. For analyzing lignin deposition in the husk, seeds were stained without de-husking; for the seed coats, seeds were first de-husked and then stained, for cross-sections, seeds were de-husked, cross-sectioned and then stained. Upon staining, seeds were observed under a stereomicroscope (Olympus SZX-ILLB200).

\section{Lignin Quantification by Acetyl bromide method}

Lignin was determined by acetyl bromide procedure as described [59] with few modifications. Briefly, from each line, ten seeds (hull+groat) were individually weighed and transferred to separate glass test tubes $(16 \times 150 \mathrm{~mm})$ fitted with PTFE-coated silicone screw cap. Perchloric acid $(70 \%, 0.08 \mathrm{ml})$ was then added followed by addition of 2 $\mathrm{ml}$ of acetyl bromide-glacial acetic acid $(1: 3 \mathrm{v} / \mathrm{v})$ and incubated at $70^{\circ} \mathrm{C}$ for $15-20 \mathrm{~min}$. The tubes were shaken gently every 5 minutes for complete dissolution. Contents were then transferred to $100 \mathrm{ml}$ volumetric flasks containing $\mathrm{NaOH}(2 \mathrm{M}, 5 \mathrm{ml})$ and acetic acid $(12 \mathrm{ml})$. The final volume was made up-to $50 \mathrm{ml}$ with acetic acid. Blank was run in conjugation with the samples without any seed. The absorbance was measured at $280 \mathrm{~nm}$ and lignin content was determined as described in Morrison et al. [60]. Means were measured from the ten seed samples and standard error calculated.

\section{Estimation of mutation frequency by RAPD analysis}

Twelve random 10-mer primers, arbitrarily named Random 1, Random 2, etc, were obtained from MWG-Biotech in Ebersberg, Germany http://www.mwgbiotech.com. Initial RAPD-PCRs were performed on DNA from non-mutagenised Belinda in order to define primers that reproducibly gave around 20 bands in a range of DNA concentrations between 10 and $200 \mathrm{ng}$. In addition, effects of different concentrations of dNTP, Platinum Taq-polymerase (Invitrogen), $\mathrm{MgCl}_{2}$, different annealing temperature and number of cycles in the PCRreaction on band pattern were tested. Random 6 was selected for further screening on genetic material isolated from the mutant library. The final protocol used was as follows: Random primer 6 (5'-AGCCAGCGAA-3', 40 $\mathrm{mM}), 10 \mathrm{ng}$ DNA in a PCR buffer of (final concentration) $2.5 \mathrm{mM} \mathrm{MgCl}_{2}, 0.8 \mathrm{mM}$ dNTP, $2 \mu \mathrm{l}$ Platinum Taq polymerase). An initial denaturation at $94^{\circ} \mathrm{C}$ for 2 minutes was followed by 45 cycles at $94^{\circ} \mathrm{C}$ for 30 seconds, $44^{\circ} \mathrm{C}$ for 1 minute, $72^{\circ} \mathrm{C}$ for 2 minutes and a final extension of $72^{\circ} \mathrm{C}$ for 5 minutes. Samples were held on ice until used. All reactions were performed in an Eppendorf Mastercycler Gradient. PCR-products were separated on a 2\% agarose gel using Electrophoresis grade agarose dissolved in Trisborate buffer at $4{ }^{\circ} \mathrm{C}$ for $3 \mathrm{hrs}$ at $6 \mathrm{~V} / \mathrm{cm}$ and then stained using $3 \times$ GelRed solution (Bionuclear Scandinavia) for ca 45 minutes and photographed.

\section{PAL and CsIF cloning}

The partial sequence of the $P A L$ was cloned from the homologue in Zea mays LOC542258 using the primers; 5'CCACGCGTCCGCTTC3', 5'CCACGAACACCTTG TCACAC3'. To elongate the obtained sequences Genome Walker ${ }^{\text {mi }}$ (Clonetech Laboratories, Inc., CA, USA) kit was used. Using this kit, gDNA library was made as per the protocol with the restriction enzyme DRA I. The following nested primers were used to walk upstream; 5'GGGTCCTTCTCGTTGATGTGCC3', 5'TCGT TGATGTG CCCGTTGCC3' and primers used to walk downstream were; 5'TGGGGATCAGCCAGGGCAAG3', 5'CA AGCCGCTGCCCATCAACA3'. The PCR amplification was done in a $25 \mu \mathrm{l}$ volume containing $5 \mathrm{ng}$ of DNA from 
genome walker, $0.75 \mu \mathrm{lggSO}_{4}, 2.5 \mu \mathrm{l} \mathrm{HiFi} \mathrm{taq} \mathrm{buffer,} 0.5$ $\mu \mathrm{l} \mathrm{dNTP}$ and $0.2 \mu \mathrm{l} \mathrm{HiFi} \mathrm{taq.} \mathrm{PCR} \mathrm{was} \mathrm{conducted} \mathrm{using}$ the Eppendorf Mastercycler Gradient as follows: heat denaturation at $94^{\circ} \mathrm{C}$ for $2 \mathrm{~min}$, followed by 30 cycles of PCR $\left(94^{\circ} \mathrm{C}\right.$ for $30 \mathrm{~s}$, annealing temperature of $72^{\circ} \mathrm{C}$ for 30 $\mathrm{s}$, extension temperature of $72^{\circ} \mathrm{C}$ for $4.5 \mathrm{~min}$ ). PCR product was cloned using the TOPO-TA kit for sequencing (Invitrogen) and sent to MWG for sequencing. A candidate EST for a $C s l F$ gene was identified in the oat EST library [20] http://www.agod.org using tBLASTX. The CslF-gene was subsequently cloned and sequenced using the GeneRacer system (Invitrogen) to obtain the partial mRNA sequence. Samples were sent to MWG Biotech (Ebersberg, Germany) for sequencing and the two resulting fragments were assembled into a single sequence using sequence overlap. The translated sequence was compared to known CslF genes in rice, wheat and barley using tBLASTx for confirmation.

PCR amplification for DNA sequencing and mutant analysis Primers for AsPAL1 were; 5'CAGTAATACGACTCACTATAGGGA GAAGGCTCGCACCCGTCCCCTTAC3' and 5'TCCACGAACACCTTGTCACAC3'. The PCR amplification was done in a $25 \mu \mathrm{l}$ volume containing $5 \mathrm{ng}$ of genomic DNA, $0.75 \mu \mathrm{lgSO}_{4}, 2.5 \mu \mathrm{l} \mathrm{HiFi} \mathrm{taq} \mathrm{buffer,}$ $0.5 \mu \mathrm{l} \mathrm{dNTP}$ and $0.2 \mu \mathrm{l} \mathrm{HiFi} \mathrm{taq.} \mathrm{PCR} \mathrm{was} \mathrm{conducted}$ using a Bio-Rad C1000 cycler as follows: heat denaturation at $94^{\circ} \mathrm{C}$ for $2 \mathrm{~min}$, followed by 30 cycles of PCR $\left(94^{\circ} \mathrm{C}\right.$ for $30 \mathrm{~s}$, annealing temperature of $65.7^{\circ} \mathrm{C}$ for $30 \mathrm{~s}$, extension temperature of $68^{\circ} \mathrm{C}$ for $1 \mathrm{~min}$ ). This resulted in a final fragment of $705 \mathrm{bp}$

The CslF6 gene was amplified using primers; 5'CGCACCCGTCCCCTTACG3' and 5'ACGACTGGC GTCTTTCCG3' as above but with an annealing temperature of $60.6^{\circ} \mathrm{C}$, an extension time of $90 \mathrm{~s}$ and 35 cycles. One of the primers was placed in the 3' UTR of the gene to decrease the chances of amplifying multiple genomes. This resulted in a final fragment of $949 \mathrm{bp}$ PCR amplified fragments were sent to Eurofins-MWG (Ebersberg, Germany) for sequencing. Chromatograms were assembled using the Sequencher application (Gene Codes Corporation) and visually inspected for unique base changes. After analysis, potential mutants were re-sequenced to confirm the existence of a mutated base.

\section{MALDI-TOF Analysis}

To screen for mutations the MassCleave ${ }^{\mathrm{tw}}$ a modified protocol from the one originally released by SEQUENOM http://www.sequenom.com was used. More specifically, samples were amplified in a standard PCR-reaction using the previously mentioned primers with either the forward or reverse primer fused at the $5^{\prime}$ end to a T7 binding domain: 5'CAGTAATACGACTCACTATAGGGAGAA GGCT3'. For AsCslF6 the PCR amplification was done in a $25 \mu \mathrm{l}$ volume containing $10 \mathrm{ng}$ of sample DNA, $0.75 \mu \mathrm{l}$ $\mathrm{MgCl}_{2}, 2.5 \mu \mathrm{l} 10 \times$ taq buffer, $0.5 \mu \mathrm{l}$ dNTP and $1 \mathrm{u}$ Platinum Taq Polymerase (Invitrogen) using primers 5'CAGTAATACGACTCACTATAGGGAGAAGG CTCGCACC CGT CC CCTTACG3', 5'ACGACTGGCGTCTTTCC G3' for the forward reaction and 5'CGCACCCGTCCCCTT ACG3', 5' CAGTAATACGACTCACTATAGGGAGAAGGCTA CGACTGGCGTCTTTCCG3' for the reverse reaction. The PCR was conducted using a thermal cycler (Eppendorf Master Cycler Gradient) as follows: heat denaturation at $94^{\circ} \mathrm{C}$ for $2 \mathrm{~min}$, followed by 45 cycles of PCR $\left(94^{\circ} \mathrm{C}\right.$ for $30 \mathrm{~s}$, annealing temperature of $60.6^{\circ} \mathrm{C}$ for $30 \mathrm{~s}$, extension temperature of $72^{\circ} \mathrm{C}$ for 1.3 min). For AsPAL1 the same protocol was used as described under sequencing and the primers 5'CAGTAATACGACTCACTATAGGGA GAAGGC TCTCC GAGCTCCAGT3', 5'CCACG AACACCTTGTCACAC3' for the forward reaction and 5'GAGAAGGACCCGCTCA ACTG3', 5'CAGTAATACGACTCACTATAGGGAGAAGG CTAGAAGGCTCCACGA ACAC CTT3' for the reverse reaction. $5 \mathrm{ul}$ of sample was treated with $1 \mathrm{ul} \mathrm{FastAP} \mathrm{P}^{\mathrm{mm}} \mathrm{SAP}$ (Fermentas) and incubated at $37^{\circ} \mathrm{C}$ for $20 \mathrm{~min}$ followed by thermal inactivation at $85^{\circ} \mathrm{C}$ for 10 minutes. $2.5 \mu \mathrm{l}$ of mastermix $(1 \mu \mathrm{l} 5 \times \mathrm{T} 7 \mathrm{R} \& \mathrm{DNA}$ buffer, $0.25 \mu \mathrm{l} 10 \mathrm{mM} \mathrm{NTP} / \mathrm{dNTP}$ mix, $0.5 \mu \mathrm{l}$ DTT, $0.25 \mathrm{~T} 7$ R\&DNA Polymerase (Epicentre Biotechnologies) and 0.5 $\mu \mathrm{l}$ RNAse-Free water) was added to $2.5 \mu \mathrm{l} \mathrm{PCR/SAP} \mathrm{mix}$ and incubated for 2 hours at $37^{\circ} \mathrm{C} \mathrm{l}$. Afterwards, $1 \mu \mathrm{l}$ of RNAse A was added to each sample followed by incubation for 1 hour at $37^{\circ} \mathrm{C}$. The sample was diluted to $15 \mu \mathrm{l}$ with RNAse free water and $2 \mathrm{mg}$ Dowex Cation Exchange Resin was added to each well. In all, four separate cleaved samples were generated from each DNA sample, two using a T7 promoter fused to a forward primer and two from a T7 promoter fused to a reverse primer. The matrix used was HPA (3-Hydroxypicolonic acid) with the concentration $35 \mathrm{mg} / \mathrm{ml}$ in $50 \%$ water and acetonitrile $(\mathrm{v} / \mathrm{v})$. Diammoniumcitrate $(7.5 \mathrm{mg} / \mathrm{ml})$ was used as co-matrix. $0.5 \mu \mathrm{l}$ of the matrix solution was added to a Bruker ${ }^{\mathrm{rm}}$ Polished Steel 384-well plate and allowed to dry completely before addition of $0.5 \mu \mathrm{l}$ sample on top of the dried HPA droplet. The finished sample was then analyzed in the positive ion mode using 400 ns delayed ion extraction. The laser was operated at a few percent over threshold values. The generated spectra were compared to the predicted mass-peaks of the sequence and several wild type spectra. Samples showing a marked deviance from wt were sequenced by Eurofins-MWG (Ebersberg, Germany).

\section{Authors' contributions}

AC optimised and performed the EMS mutagenesis and was responsible for the logistics of the whole operation. AC, PS, MB, MN, TC and OO participated out-sowing, seed collection and harvesting of the $\mathrm{M} 1$ and $\mathrm{M} 2$ populations and helped with the DNA preparations. AC cloned AsPAL1 and identified the low 
lignin mutants and $\mathrm{V}$ made the lignin quantifications. PS cloned AsCsIF6 and conducted the RAPD experiments. PS and ML optimised the MALDI-TOF protocol for TILLING and identified the mutations in AsPAL1 and AsCsIF6 genes. OO planned and supervised the work and wrote the manuscript together with $A C$ and PS. All authors read and approved the final manuscript.

\section{Acknowledgements}

The authors would like to thank Luca Comai, Bradley Till and the rest of the TILLING group at Fred Hutchinson Cancer Research Center, Seattle, USA for helpful discussions. We also thank Karen Brackley, Göteborg Universiy for correcting the language and Mats Andersson, Chalmers University of Technology for the use of the MALDI-TOF apparatus.

This work was supported by grants from The Swedish Farmers Supply and Crop Marketing Co-operative (SLF), the Swedish Research School in Genomics and Bioinformatics and the Swedish Research Council for Environment, Agricultural Sciences and Spatial Planning (FORMAS) given to OO.

\section{Author Details}

'Department of Cell and Molecular Biology, Göteborg University, S-40530 Göteborg, Sweden, ${ }^{2}$ Department of Plant and Environmental Sciences, Göteborg University, S-40530, Göteborg, Sweden, ${ }^{3}$ CropTailorAB, Erik Dahlbergsgatan 11A, SE41126 Göteborg, Sweden, ${ }^{4}$ Department of Chemical and Biological Engineering, Chalmers University of Technology, S-41296, Göteborg, Sweden and ${ }^{5}$ Current Address: Microbiology Research Institute, Guangxi Academy of Agricultural Sciences, Nanning, Guangxi 530007, China

Received: 27 July 2009 Accepted: 12 May 2010

Published: 12 May 2010

\section{References}

1. Grass phylogeny working group [http://www.umsl.edu/services/ kellogg/gpwg/default.htm]

2. FAO: Food and Agriculture Organization. ProdSTAT; FAOSTAT 2008.

3. World Agricultural Production [http://www.fas.usda.gov/wap arc.asp]

4. Suttie JM, Reynolds SG: Fodder oats: a world overview. In FAO Plant Production and Protection Series FAO; 2004:266.

5. Aman $P$, Graham H: Analysis of total and insoluble mixed-linked $(1,3 ; 1,4)$ beta.-D-glucans in barley and oats. Journal of Agricultural Food Chemistry 1987, 35(5):704-709.

6. Brown L, Rosner B, Willett WW, Sacks FM: Cholesterol-lowering effects of dietary fiber: a meta-analysis. Am J Clin Nutr 1999, 69(1):30-42.

7. Davidson MH, Dgan LD, Burns JH, Bova J, Story K, Drennan KB: The hypocholesterolemic effects of beta-glucan in oatmeal and oat bran. A dose-controlled study. JAMA 1991, 265(14):1833-1839.

8. Ripsin CM, Keenan JM, Jacobs DR Jr, Elmer PJ, Welch RR, Van Horn L, Liu K, Turnbull WH, Thye FW, Kestin M, et al:: Oat products and lipid lowering. A meta-analysis. JAMA 1992, 267(24):3317-3325.

9. Shewry PR, Piironen V, Lampi AM, Nystrom L, Li L, Rakszegi M, Fras A, Boros D, Gebruers K, Courtin CM, et al:: Phytochemical and fiber components in oat varieties in the HEALTHGRAIN Diversity Screen. J Agric Food Chem 2008, 56(21):9777-9784.

10. Leeds AR: Oats reassessed. Nutrition Bulletin 2007, 13:153-160.

11. Stoskopf NC, Nathaniel RK, Reinbergs E: Comparison of Spring Wheat and Barley with Winter Wheat: Yield Components in Ontario1. Agron J 1974, 66:748-750.

12. Watson DJ, Thorne GN, French SAW: Analysis of Growth and Yield of Winter and Spring Wheats. Annals of Botany 1963, 27:

13. Casler MD, Jung HJ: Relationships of fibre, lignin, and phenolics to in vitro fibre digestibility in three perennial grasses. Animal feed science and technology 2006, 125(1-2):151-161.

14. Jung $\mathrm{HJ}$ : Forage lignins and their effect on fiber digestibility. J Agron 1989, 81:33-38.

15. van Egmond HP, Schothorst RC, Jonker MA: Regulations relating to mycotoxins in food: perspectives in a global and European context. Anal Bioanal Chem 2007, 389(1):147-157.

16. Rines HW, Molnar SJ, Tinker NA, Phillips RL: Oat. In In Genome Mapping and Molecular Breeding in Plants, Cereals and Millets Volume 1. Edited by: Kole C. Berlin: Springer-Verlag; 2006:211-242.

17. Tinker NA, Kilian A, Wight CP, Heller-Uszynska K, Wenzl P, Rines HW, Bjornstad A, Howarth CJ, Jannink JL, Anderson JM, et al.: New DArT markers for oat provide enhanced map coverage and global germplasm characterization. BMC Genomics 2009, 10:39.

18. Bennett MD, Smith JB: Nuclear dna amounts in angiosperms. Philos Trans R Soc Lond B Biol Sci 1976, 274(933):227-274.

19. Leggett JM: Classification and Speciation of Avena. In Oat Science and Technology, Agronomy Monograph 33 Edited by: Sorrells ME, Marshall HG Madison WI: American Society of Agronomy and Crop Science; 1992:29-52

20. Brautigam M, Lindlof A, Zakhrabekova S, Gharti-Chhetri G, Olsson B, Olsson O: Generation and analysis of 9792 EST sequences from cold acclimated oat, Avena sativa. BMC Plant Biol 2005, 5:18.

21. Hoffmann GR: Genetic effects of dimethyl sulfate, diethyl sulfate, and related compounds. Mutat Res 1980, 75(1):63-129.

22. McCallum CM, Comai L, Greene EA, Henikoff S: Targeting induced local lesions IN genomes (TILLING) for plant functional genomics. Plant Physiol 2000, 123(2):439-442.

23. Bentley A, MacLennan B, Calvo J, Dearolf C: Targeted recovery of mutations in Drosophila. Genetics 2000, 156(3):1169-1173.

24. Greene EA, Codomo CA, Taylor NE, Henikoff JG, Till BJ, Reynolds SH, Enns LC, Burtner C, Johnson JE, Odden AR, et al:: Spectrum of chemically induced mutations from a large-scale reverse-genetic screen in Arabidopsis. Genetics 2003, 164(2):731-740.

25. Caldwell DG, McCallum N, Shaw P, Muehlbauer GJ, Marshall DF, Waugh R: A structured mutant population for forward and reverse genetics in Barley (Hordeum vulgare L.). Plant J 2004, 40(1):143-150.

26. Talame V, Bovina R, Sanguineti MC, Tuberosa R, Lundqvist U, Salvi S: TILLMore, a resource for the discovery of chemically induced mutants in barley. Plant Biotechnol J 2008, 6(5):477-485.

27. Horst I, Welham T, Kelly S, Kaneko T, Sato S, Tabata S, Parniske M, Wang TL: TILLING mutants of Lotus japonicus reveal that nitrogen assimilation and fixation can occur in the absence of nodule-enhanced sucrose synthase. Plant Physiol 2007, 144(2):806-820.

28. Perry JA, Wang TL, Welham TJ, Gardner S, Pike JM, Yoshida S, Parniske M: A TILLING reverse genetics tool and a web-accessible collection of mutants of the legume Lotus japonicus. Plant Physio/ 2003, 131(3):866-871.

29. Slade AJ, Fuerstenberg SI, Loeffler D, Steine MN, Facciotti D: A reverse genetic, nontransgenic approach to wheat crop improvement by TILLING. Nat Biotechnol 2005, 23(1):75-81.

30. Till BJ, Reynolds SH, Weil C, Springer N, Burtner C, Young K, Bowers E, Codomo CA, Enns LC, Odden AR, et al:: Discovery of induced point mutations in maize genes by TILLING. BMC Plant Biol 2004, 4:12.

31. Suzuki T, Eiguchi M, Kumamaru T, Satoh H, Matsusaka H, Moriguchi K, Nagato Y, Kurata N: MNU-induced mutant pools and high performance TILLING enable finding of any gene mutation in rice. Mol Genet Genomics 2008, 279(3):213-223.

32. Till BJ, Cooper J, Tai TH, Colowit P, Greene EA, Henikoff S, Comai L: Discovery of chemically induced mutations in rice by TILLING. BMC Plant Biol 2007, 7:19.

33. Triques K, Sturbois B, Gallais S, Dalmais M, Chauvin S, Clepet C, Aubourg S, Rameau C, Caboche M, Bendahmane A: Characterization of Arabidopsis thaliana mismatch specific endonucleases: application to mutation discovery by TILLING in pea. Plant J 2007, 51(6):1116-1125.

34. Cooper UL, Till BJ, Laport RG, Darlow MC, Kleffner JM, Jamai A, El-Mellouk $T$, Liu S, Ritchie R, Nielsen N, et al:: TILLING to detect induced mutations in soybean. BMC Plant Biol 2008, 8:9.

35. Jalani BS, Frey KJ, Bailey TB Jr: Contribution of growth rate and harvest index to grain yield of oats (Avena sativa L.) following selfing and outcrossing of M1 plants. Euphytica 1979, 28(2):219-225

36. Boom D van den, Ehrich M: Discovery and identification of sequence polymorphisms and mutations with MALDI-TOF MS. Methods Mol Biol 2007, 366:287-306.

37. Guo D, Chen F, Inoue K, Blount JW, Dixon RA: Downregulation of caffeic acid 3-O-methyltransferase and caffeoyl $\mathrm{CoA}$ 3-O-methyltransferase in transgenic alfalfa. impacts on lignin structure and implications for the biosynthesis of $\mathrm{G}$ and S lignin. Plant Cell 2001, 13(1):73-88,

38. Rowe JB, Crosbie GB: The digestibility of grain of two cultivars of oats differing in lignin content. Australian Journal of Agricultural Research 1988, 39(4):639-644

39. Nilsson U, Johansson M, Nilsson A, Bjorck I, Nyman M: Dietary supplementation with beta-glucan enriched oat bran increases faecal 
concentration of carboxylic acids in healthy subjects. Eur J Clin Nutr 2008, 62(8):978-984.

40. Doyle JJ, Doyle JL, Bailey-Hortorium LH: Isolation of plant DNA from fresh tissue. Focus 1990, 12:13-15.

41. Speer EO: A method of retaining phloroglucinol proof of lignin. Stain Technol 1987, 62(4):279-280.

42. Dence CW: The determination of lignin. In Methods in lignin chemistry Edited by: Lin SY, Dence CW. heidelberg: Springer Verlag; 1992:33-61.

43. Thompson RK, Mustafa AF, McKinnon JJ, Maenz D, Rossnagel B: Genotypic differences in chemical composition and ruminal degradability of oat hulls. Can J Anim Sci 2000, 80:377-379.

44. Kumar P, Henikoff S, Ng PC: Predicting the effects of coding nonsynonymous variants on protein function using the SIFT algorithm. Nat Protoc 2009, 4(7):1073-1081.

45. PSSM viewer [http://www.ncbi.n/m.nih.gov/Class/Structure/pssm/ pssm viewer.cgil

46. Henikoff S, Comai L: Single-nucleotide mutations for plant functional genomics. Annu Rev Plant Biol 2003, 54:375-401.

47. Rajhathy $\mathrm{T}$, Hugh $\mathrm{T}$ : Cytogenetics of oats (avena L.). Q = Ottawa: la Societe de Genetique du Canada; 1974.

48. Nomura T, Ishihara A, Yanagita RC, Endo TR, Iwamura H: Three genomes differentially contribute to the biosynthesis of benzoxazinones in hexaploid wheat. Proc Natl Acad Sci USA 2005, 102(45):16490-16495.

49. Monties B: Plant Phenolics. In Methods in Plant Biochemistry Volume 1. Edited by: Dey PM, Harborne JB. New York: Academic Press; 1989:113-157.

50. Hatfield R, Fukshima RS: Can lignin be accuretely measured? Crop science 2005, 45(3):832-839.

51. Neish WJ, Key L: Polyamines and glutathione in tissues of lactating rats (Rattus rattus) and in the Rd-3 adcites tumour. Comp Biochem Physiol 1968, 27(3):709-714.

52. Burton RA, Wilson SM, Hrmova M, Harvey AJ, Shirley NJ, Medhurst A Stone BA, Newbigin EJ, Bacic A, Fincher GB: Cellulose synthase-like CsIF genes mediate the synthesis of cell wall $(1,3 ; 1,4)$-beta-D-glucans. Science 2006, 311(5769):1940-1942.

53. Doblin MS, Pettolino FA, Wilson SM, Campbell R, Burton RA, Fincher GB, Newbigin E, Bacic A: A barley cellulose synthase-like CSLH gene mediates $(1,3 ; 1,4)$-beta-D-glucan synthesis in transgenic Arabidopsis. Proc Natl Acad Sci USA 2009, 106(14):5996-6001.

54. Till BJ, Reynolds SH, Greene EA, Codomo CA, Enns LC, Johnson JE, Burtner C, Odden AR, Young K, Taylor NE, et al: Large-scale discovery of induced point mutations with high-throughput TILLING. Genome Res 2003, 13(3):524-530.

55. Colbert T, Till BJ, Tompa R, Reynolds S, Steine MN, Yeung AT, McCallum CM, Comai L, Henikoff S: High-throughput screening for induced point mutations. Plant Physiol 2001, 126(2):480-484.

56. Stanssens P, Zabeau M, Meersseman G, Remes G, Gansemans Y, Storm N, Hartmer R, Honisch C, Rodi CP, Bocker S, et al.: High-throughput MALDITOF discovery of genomic sequence polymorphisms. Genome Res 2004, 14(1):126-133

57. Tost J, Gut IG: Genotyping single nucleotide polymorphisms by MALDI mass spectrometry in clinical applications. Clin Biochem 2005, 38(4):335-350

58. Zhong R, lii WH, Negrel J, Ye ZH: Dual methylation pathways in lignin biosynthesis. Plant Cell 1998, 10(12):2033-2046.

59. liyama K, Wallis AFA: An improved acetyl bromide procedure for determining lignin in woods and wood pulps. Wood Science and Technology 1988, 22(3):271-280.

60. Morrison IM: A semi-micro method for the determination of lignin and its use in predicting the digestibility of forage crops. J Sci Food Agric 1972, 23(6):455-463.

doi: $10.1186 / 1471-2229-10-86$

Cite this article as: Chawade et al., Development and characterization of an oat TILLING-population and identification of mutations in lignin and ?-glucan biosynthesis genes BMC Plant Biology 2010, 10:86

\section{Submit your next manuscript to BioMed Central} and take full advantage of:

- Convenient online submission

- Thorough peer review

- No space constraints or color figure charges

- Immediate publication on acceptance

- Inclusion in PubMed, CAS, Scopus and Google Scholar

- Research which is freely available for redistribution

Submit your manuscript at www.biomedcentral.com/submit
C Biomed Central 